\title{
Is the "BE compound tense" in Xhosa (Nguni) a Serial Verb Construction, or not?
}

Key words: serial verb constructions; Xhosa (Nguni, Bantu); typology; cognitive linguistics

Słow a klu c ze: seryjne konstrukcje czasownikowe; język Xhosa (Nguni, Bantu); typologia; lingwistyka kognitywna

\section{Introduction}

Nguni languages (Xhosa, Zulu, Swati, and Ndebele) ${ }^{1}$ include in their verbal systems a construction widely known under the term 'the compound (near past) tense' (Visser 2005, 2015, Oosthuysen 2016), which can be exemplified by the forms ndibe ndidlala and bendidlala 'I was playing'. Given its most persistent marker - i.e. the element be (see Section 3) - I will refer to this construction as the BE gram(matical form).

In two seminal typological studies written by Bernd Heine (1993) and Alexandra Aikhenvald (2006), the BE gram was classified as a serial verb construction (SVC). Specifically, drawing on evidence from Zulu, Heine (1993: 37-38) views the BE gram as an instantiation of a "serial schema" -

1 The Nguni languages belong to the Southern branch of the Bantu family (Guthrie 1970, Bastin, Coupez \& Mann 1999). 
that is, a structure that involves two (or more) finite verbs inflected in person, number, tense, or other categories. In agreement with the primary function of "serial schemas", the BE gram is understood as an expression of aspect - the progressive past, to be exact. Following Heine's view, Alexandra Aikhenvald (2005: 31-32) uses the BE gram to illustrate the process of grammaticalization of asymmetrical SVCs and the development of one of their verbal components - the so-called minor verb, such as $b a$ 'be' in the Nguni construction - into a tense, aspect or mood marker.

Contrary to these two widely acclaimed studies, the BE gram has not to my knowledge - been analyzed as an SVC by scholars working in the area of the Nguni verbal system. In Xhosa, the BE gram has never been defined as an SVC, but rather as a compound tense built around an auxiliary (the verb $b a$ 'be') and another lexical verb (McLaren \& Welsh 1955: 90-93, Louw \& Jubase 1963: 221, Riordan, Mathiso \& Davey 1969: 247-249, Du Plessis 1978: 131, Du Plessis \& Malinga 1978: 97-100, Visser 2005, 2015 : 13-15, Oosthuysen 2016: 237-241, 288). An analogous analysis may be found in research dedicated to the Zulu language (Van Eeden 1956: 320, Doke 1981: 190-195, Posthumus 1982, 1983, 1990, 2006, 2008, Taljaard \& Bosch 1988: 149-150, Poulos \& Msimang 1998, Hall 2005, Groenewald 2014), as well as Swati (Taljaard, Khumalo \& Bosch 1991: 144-147) and Ndebele (Pelling \& Pellig 1974: 148-149, Ziervogel 1959: 145). The understanding of the Nguni BE gram in terms of a periphrasis composed of an auxiliary and a lexical verb also appears in comparative studies devoted to the (Southern) Bantu family (Gowlet 2003, Nurse 2008: 132-133).

The present paper aims to determine whether the $\mathrm{BE}$ gram is - or is not - an instantiation of an SVC by analyzing data from Xhosa. Given the close genetic relationship between all the Nguni languages, the conclusions drawn from Xhosa can be extrapolated to the other members of the branch.

In order to achieve its objective, the paper will be organized as follows: In Section 2, I will familiarize the reader with the framework underlying my research. In Section 3, I will present the evidence from Xhosa. In Section 4, the results of this evidence will be evaluated within the adopted framework, and the question of the categorical status of the BE gram will be answered. Lastly, in Section 5, I will draw main conclusions, showing how this research contributes to the broader theory of SVCs. 


\section{Framework - the prototype model of SVC}

In this paper, I will adopt a dynamic radial-network approach to the category of SVCs (Aikhenvald 2006, Aikhenvald \& Dixon 2006, Dixon 2006, Andrason 2018a, 2018b) developed at the crossroads of cognitive linguistics and grammaticalization theory. ${ }^{2}$

In this approach, the SVC category is primarily structured around its most exemplary representative - the prototype. Drawing on comprehensive, typological observations provided by Aikhenvald (2006), Dixon (2006), and Bisang (2009), I have argued (Andrason 2018a, 2018b) that the prototype of an SVC exhibits a number of characteristics which can be grouped in two sets. One set contains features that make patent the less cohesive profile of SVCs if compared with other, more synthetic verbal grams. Specifically, the prototype of an SVC is bi-verbal, consisting of two (or more) finite verbs (Aikhenvald 2006). ${ }^{3}$ The use of such verbs is, furthermore, not limited to a respective SVC. On the contrary, the verbal components of an SVC can occur on their own, exhibiting, in such cases, their full, lexical meanings (ibid. 1). The other set contains properties that are responsible for the more cohesive facet of the SVC's grammatical profile. The cohesion exhibited by an SVC may, itself, be related to morphosyntax, semantics, and phonology. Morphosyntactically, the SVC prototype exhibits a single TAM and polarity value, as well as a unitary argument structure. That is, the components of an SVC cannot be marked by different, especially incompatible, TAM categories (ibid. 8) ${ }^{4}$, nor can they express negative and positive polarity, separately - an independent

${ }^{2}$ For a critique of the theories formulated by Aikhenvald (2006), Dixon (2006), and Bisang (2009), and an alternative approach to SVCs see Haspelmath (2016). The understanding of grammaticalization adopted in this paper follows the views advanced by Hopper \& Traugott (2003) and Bybee (2010). Concerning the concepts of radial networks, (dynamic) semantic maps, and grammatical prototypes consult Haspelmath (2003), Croft (2003), Taylor (2003), Narrog \& Van der Auwera (2011), Janda (2015), and Andrason (2016a, 2016b).

3 The term 'bi-verbiness' has been coined by the author of this paper in his previous study dedicated to SVCs in Polish (Andrason 2018a). An alternative term could be 'bifiniteness'.

${ }^{4}$ Moreover, an SVC is not restricted to a particular TAM category but appears in a variety of TAM categories that are available in a particular language (Aikhenvald 2006: 56). 
choice or contrast in TAM and polarity is impossible (ibid. 8-9). Similarly, the individual components of an SVC cannot project duplicate roles and govern separate arguments. Instead, the internal and external arguments - especially the subject - belong to the entire construction (ibid. 12-14, 56). Semantically, an SVC constitutes "one assertion". It expresses a single event rather than a sequence or composition of events (ibid. 10). Phonologically, an SVC is characterized by a cohesive intonation typical of mono-verbal clauses, i.e. with no pause or contouring (ibid. 7). ${ }^{5}$ Overall, an SVC acts as a single predicate and a single clause. This, on the one hand, precludes any type of syntactic dependency, such as subordination, embedding or nominalization (e.g. the use of participles, infinitives, or verbal nouns). On the other hand, it differentiates SVCs from coordinated constructions as well as from consecutivization and complementization (ibid. 5-7).

The above-mentioned characteristics - which, in their totality, distinguish the SVC prototype most efficiently from other grammatical categories and their respective prototypes - can be used to test constructions for their membership in the SVC category. Constructions that comply with the prototype to the fullest extent constitute canonical instantiations of the SVC category. In contrast, constructions that exhibit some of the features mentioned in the previous paragraph - or exhibit all the features albeit only to a certain extent are less canonical or non-canonical. Crucially, all such instantiations are contained by the category, merely differing in the degree of their category-hood. Overall, the question of belonging to the category is not approached from the perspective of binarism - i.e. either as inclusion or exclusion. It is rather approached in terms of gradience - i.e. categorial belonging being a function of degree. As a result, instantiations of SVCs found across languages deliver a radial network - a map that emanates from the categorial center occupied by canonical representatives to the periphery containing non-canonical representatives through an intermediate zone of gradually less canonical representatives.

This radial network, which enables a meaningful structuring of the crosslinguistic variation of SVCs, has a dynamic - i.e. evolutionary or grammaticalization-based - foundation. Instantiations that exhibit different degrees of compliance with the SVC prototype, and range from canonical to non-canonical,

5 Inversely, an SVC does not exhibit an intonational pattern that is found in a sequence of clauses. 
form a grammaticalization pathway leading to that prototype, and subsequently further away from it. Generally, the grammaticalization path of SVCs concerns the increase of cohesion through the strengthening of phonological, semantic, and morphosyntactic unity (Aikhenvald 2006: 56, 2011: 22). That is, SVCs constitute a transitory phase on the development from non-cohesive, multi-clausal, multi-propositional, and multi-verbal constructions (e.g. coordination or subordination; Aikhenvald 2006, 2011, Andrason 2018a, 2018b) towards fully cohesive, mono-clausal, mono-propositional, and mono-verbal constructions (e.g. synthetic TAM grams; see Figure 1 below).

Instantiations of the SVC category that exhibit a less cohesive structure attest to less advanced evolutionary stages. They are, in turn, fairly closely related to the diachronic source of the path (Aikhenvald 2006, 2011). Such instantiations inhabit the initial section of the grammaticalization continuum of SVCs. The prototype of SVCs - and its canonical instantiations - occupy a more advanced stage on the continuum, i.e. its middle section. That is, although a canonical SVC exhibits various cohesive features (e.g. monoclausality, mono-propositionality, as well as a unitary TAM, polarity and argument structure), it still constitutes a bi-verbal schema whose components may act independently. As grammaticalization continues, canonical SVC constructions may evolve into fully cohesive structures, drifting away from the SVC prototype towards the prototype of mono-verbiness, exemplified by single-verb, synthetic tenses, aspects, or moods (Aikhenvald 2006). SVCs with more cohesive profiles attest to such more advanced evolutionary stages. In a dynamic representation, they occupy sections of the continuum that are closer to the output of the grammaticalization process (Andrason (forthcoming); see Figure 1). ${ }^{6}$

Given the gradient nature of the dynamic radial network discussed above, any borderline separating the stages postulated on the continuum - and thus, the categories that jointly populate it - is arbitrary. The only thing that realistically exists is the variation attested crosslinguistically or language-specifically, and the continuum itself. The transition from one stage to another, or from one category to another, is fuzzy (cf. Andrason 2016a).

6 Thus, non-canonical instantiations either attest to the process of becoming an SVC (movement towards the prototype) or constitute developmental stages subsequent to an SVC (movement away from the prototype). 
Crucially, when evolving, language-specific constructions do not "jump" from one stage/category to another. Rather, they accumulate characteristics typical of certain (consecutive) sections of the continuum. Therefore, a single construction present in a language can be simultaneously mapped onto more than a single point along the continuum. That is, it may comply with different categories and their prototypes, or it may comply with a single category, although matching that particular category's prototype to different degrees (Andrason 2018a: 24). ${ }^{7}$

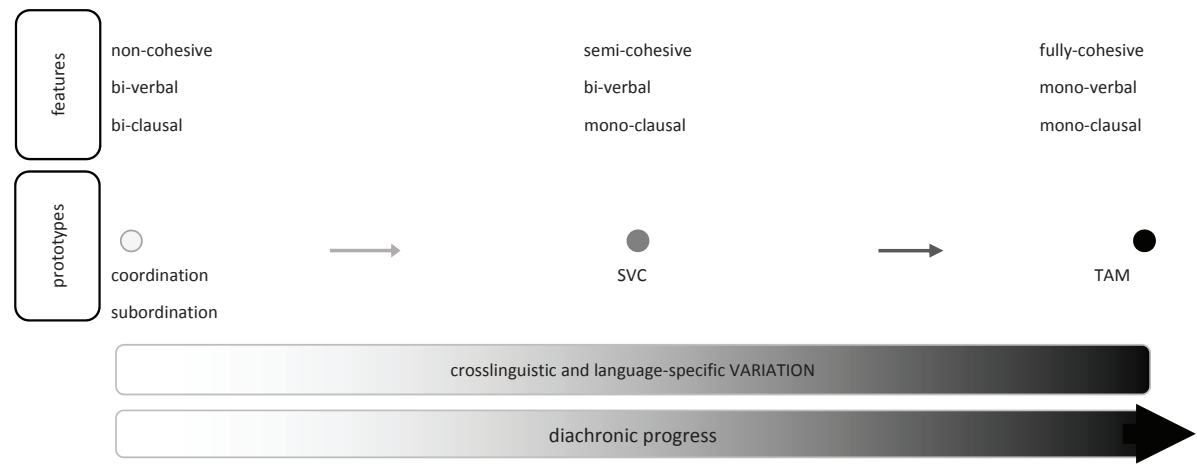

Figure 1: A dynamic representation of SVC (adapted from Andrason 2018a) $^{8}$

\section{Evidence - the BE gram in Xhosa}

In the present section, I will describe the semantic, syntactic, morphological and phonological properties of the BE gram. In particular, I will test the $\mathrm{BE}$ gram for the features that have been postulated as inherent to the SVC

7 In fact, even a single use may allow for more than one interpretation, thus attesting to a section of the continuum, not only a single point.

8 This continuum allows for two interpretations: a diachronic one and a synchronic one. The diachronic interpretation refers to the evolution of a gram or a set of grams. The synchronic interpretation represents a synchronic variation attested in a specific language or across languages. As there are various features determining the compliance with the SVC prototype, the continuum could be depicted as multi-dimensional (Aikhenvald 2006: 56). For the sake of simplicity, the continuum is represented as one-dimensional (see a similar cline in Aikhenvald 2011: 22). 
prototype (see Section 2). The response of the BE gram to these features and its overall semantic-morphosyntactic-phonological profile - will enable me to determine the categorial status of this construction, thus answering the question of whether it does, or does not, constitute an instantiation of SVC. Firstly, I will study the properties that are responsible for the less cohesive facet of SVCs if compared to more advanced, synthetic verbal grams (Section 3.1). Secondly, I will test the BE gram for the various features that demonstrate the morphosyntactic, semantic and phonological cohesion of SVCs (Section 3.2).

\subsection{Less cohesive properties of SVC}

\subsubsection{Bi-verbiness}

To begin with, it should be noted that the $\mathrm{BE}$ gram exhibits two main structural types: the full (analytical) form and the contracted (synthetic) form (Jordan 1966, Oosthuysen 2016). As will be evident from the subsequent discussion, the grammatical profiles of these two types are distinct.

From a historical perspective, the full variant is original. The contracted type is diachronically secondary, constituting a posterior development of an analytical expression into a synthetic form. Although speakers currently have access to the two construction-types, in speech, less formal registers, and non-literary genres, the contracted forms are significantly more common than the full forms (Jordan 1966: 181-182, Oosthuysen 2016).

The full form consists of two inflected finite verbs. The first component $(\mathrm{V}-1)$ is the base $-b a$ 'be' inflected in the short variant $(-e)$ of the so-called perfect or near-past tense (1.a-c; Visser 2005, Oosthuysen 2016). ${ }^{9}$ Most commonly, the perfect / near past of V-1 appears in the indicative or the relative mood, being marked by subject prefixes typical of the indicative or relative tenses, respectively. The other verb (V-2) is inflected in the situative (Visser 2015, Oosthuysen 2016), which is also referred to as the participial (Riordan, Mathiso \& Davey 1969: 238, Visser 2005) (1.a). The situative is marked by

9 There is another compound tense in Xhosa in which the verb $b a$ 'be' is inflected in the so-called remote A tense (Jordan 1966, Visser 2005, Oosthuysen 2016). Even though the two constructions are systemically related, the present study deals only with the compound tense that is built around the perfect / near past form of the verb $b a$. 
a set of subject prefixes and the morpheme $s(i)$. The subject prefixes of the situative are often identical to the prefixes found in the indicative with the exception of classes 1(a), 2(a), and 6, where the prefixes $e$-, be-, $e$ - are used instead of $u$-, $b a$ - and $a$-, respectively. The distinctive morpheme $s(i)$ appears exclusively in monosyllabic bases (-si-tya 'eat(ing)') and bases beginning with a vowel (-s-enza 'do(ing)'). In all the other cases, the situative present morphology is identical to that of the indicative null present tense (e.g. ndidlala 'I play' or '(I) playing'). In the BE gram, the situative of V-2 may appear in three variants: the null present $(1 . a)^{10}$, the perfect / near past (1.b), or the future (1.c). ${ }^{11}$
(1) a. Ndi-b-e
ndi-dlala
I.SA-be-PERF
I.SA.SIT-play
I was playing
b. Ndi-b-e
ndi-dlal-ile
I.SA-be-PERF I.SA.SIT-play-PERF
I had played
c. Ndi-b-e
ndi-za
ku-dlala
I.SA-be-PERF
I.SA.SIT-come
INF-play
I was going to play

From the above discussion it is evident that the full type of the BE gram complies with the bi-verbiness of the SVC prototype. That is, both components of the construction are finite, being inflected in person or noun class referring to the subject - the Xhosa equivalent of the person, number, and

10 The term 'null' implies that there is no overt TAM morpheme marking this type of present, e.g. ndi-hamba 'I go' of the verb hamba 'go' (compare with ndi-ya-hamba which contains an overt present-tense morpheme $y a$ ). For a distribution of the two types of the present tense consult Visser $(2005,2015)$ and Oosthuysen (2016).

11 The future is an analytic construction composed of the auxiliary verb $z a$ 'come' or $y a$ 'go' inflected in the null present, and the infinitive of the main (lexical) verb (Visser 2005, Oosthuysen 2016). Therefore, the situative future consists of the situative present of the auxiliary $z a$ or $y a$ and the infinitive of the main verb, e.g. $e$-za kudlala 'he (is) going to play'. 
gender inflection of Indo-European languages. Both V-1 and V-2 are likewise inflected in tense, aspect or mood.

The other morphosyntactic type of the BE gram is the contracted form. Two sub-variants of the contracted type can be distinguished. With strong noun classes (i.e. those whose subject prefixes begin with a consonant), the person/noun-class inflection of $\mathrm{V}-1 b a$ 'be' (i.e. $n d i-b e)$ is absent and the element $b e$ is agglutinated to the verb that, in the full form, appears as V-2 (2.a; Oosthuysen 2016). With weak classes, the original subject prefix of $b a$ is preserved, while the vocalic part of the element be is lost, being merged with the subject prefix of the original V-2 inflected in the situative (2.b; Oosthuysen 2016). There is, additionally, a further variant found in weak classes 1(a) and 6. With these two classes, the initial vowel of the subject agreement exhibited by the verb $b a$ is assimilated to the vowel found in the original subject prefix of V-2: $u$-be e-R $>u$-be-R $>e-b e-\mathrm{R}$ and $a$-be $e-\mathrm{R}>a-b e-\mathrm{R}>e-b e-\mathrm{R}(2 . c) .{ }^{12}$ Diachronically, forms with vowel assimilation are secondary, having developed from the primary non-assimilated ones (Jordan 1966: 183).

(2) a. Be-ndi-dlala be-I.SA.SIT-play

I was playing

b. U-b-e-dlala

1.SA-be-1.SA.SIT-play

He was playing

c. E-b-e-dlala

1.SA.ASSIM-be-1.SA.SIT-play

He was playing

Given its systematic use throughout the entire contracted paradigm, the element - be- can be reinterpreted as an invariant TAM marker rather than a lexical form of the verb $b a$ 'be'. This is evident in the strong contracted

12 As a result, the subject agreement of V-1 appears as if it were in the situative. However, the inflectional assimilation of $\mathrm{V}-1$ never leads to the presence of the morpheme $s i$ on the verb $b a$. 
forms, as the subject agreement markers of V-1 $b a$ have been lost. This reinterpretation is made manifest in the gloss of example (3.a), where the element -be is glossed as BE (i.e. an invariant TAM marker) instead of 'be' (i.e. a form of the verb $b a$ 'be'). Weak contracted forms (both assimilated and non-assimilated) may also be analyzed in a similar manner. That is, in analogy to the strong classes and the paradigmatization of V-1 $b a$, the slot $b e$ in the weak contracted forms may be explained as a constant TAM morpheme, specific to the $\mathrm{BE}$ gram (3.b-c). Nevertheless, with weak classes, the interpretation of be as an inflected verb $b a$ (as in 2.b-c) is also possible, since the subject agreement markers of $b a$ are still present. ${ }^{13}$

(3) a. Be-ndi-dlala BE-I.SA-play

I was playing

b. U-be-dlala

1.SA-BE-play

$\mathrm{He} / \mathrm{she}$ was playing

c. E-be-dlala

1.SA-BE-play

$\mathrm{He} / \mathrm{she}$ was playing

It should be noted that in the contracted type, the situative morphology of the original V-2 is still patent, as monosyllabic verbs (4.a) and verbs that start with a vowel (4.b) exhibit the morpheme $s(i)$ - a typical marker of the situative.

(4) a. Be-ndi-si-tya

BE-I.SA-SIT-eat

I was eating

13 As was the case of the full type, the contracted forms also allow for three subtypes depending on the original form of the situative V-2, namely, the present (bendihamba), the perfect (bendi-hambile), and the future (bendiza kuhamba). 
b. Be-ndi-senza

BE-I.SA-SIT-do

I was doing

In general, the overt bi-verbiness of the contracted type is significantly less evident than was the case with the full type. In various cases, the element be functions as an invariant and synchronically indeclinable component of the gram, rather than an inflected form of the lexical verb $b a$. Strong contracted forms attest most clearly to this phenomenon as the person / noun-class subject inflection is lost. In such instances, the person / noun-class inflection is marked only once per construction, before the lexical verb (originally V-2). Since V-1 seems to have lost its verbal status, the entire bi-verbal structure assumes a mono-verbal interpretation. With weak classes, two interpretations seem possible: the inflection is marked twice (as in the full type of the BE gram) or only once, in analogy to the strong contracted forms. Such behavior would arguably attest to an intermediate grammaticalization stage in the process during which the sequence of originally independent verbs gradually merge into an indissoluble synthetic form. In that intermediate stage, two positions on the grammaticalization cline are available for a construction: a less advanced one (attesting to bi-verbiness) and another, more advanced one (attesting to mono-verbiness). ${ }^{14}$

\subsubsection{The independency of the components of SVCs}

Both components of the full type of the BE gram can occur on their own, exhibiting, in such cases, their full lexical meaning. This is evident for $\mathrm{V}-2$ which always determines the semantic type of an event expressed by the BE gram, be it action, situation, or condition (see Section 3.2.1). The following pairs of examples demonstrate the use of V-2 in the BE gram and its independent use: e.g. bendisitya 'I was eating' - ndityile 'I ate', bendihamba

14 One should note that in most teaching materials for first and second language learners (Jordan 1966, Bryant 2007, Visser 2015, Oosthuysen 2016), the contracted forms are presented as fused TAM and person markers specific of the BE gram. That is, the element be is explained as an invariant part of the complex inflectional marker that must be learned in its totality (and not as a sequence of inflected verbs). The only genuine verbal component that could be inflected is the main verb, which was originally V-2. 
'I was walking' - ndahamba 'I walked', bendilele 'I was sleeping' - ndilala 'I sleep', or bendilambile 'I was hungry' - ndilambile 'I am hungry', etc.

The V-1 $b a$ may also be used independently of the BE gram. Specifically, $b a$ may appear as a main verb with the existential meaning 'be; become' (5.a) or the locative meaning 'be (in a place)' (5.b). It can also be used in other senses that constitute meaning extensions of the afore-mentioned existential/ locative values, e.g. 'be like, resemble' (5.c).

(5)

a. Ndi-b-e s-e-Kapa

I.SA-be-PERF BF-LOC-Cape.Town

I was in Cape Town

b. U-b-e m-khulu

1.SA-be-PERF 1ADJ-big

He has become big

c. USipho u-b-e ku-yise (adapted from

Tshabe 2006: 62)

1a.Sipho 1.SA-be-PERF to-his.father

Sipho is like (i.e. resembles) his father

In its lexical uses, $b a$ may be inflected in the perfect / near past tense, exhibiting the form SA-be. This demonstrates that the verb $b a$ in general, or in the inflected form SA-be more specifically, is not limited to the BE gram. On the contrary, it continues to be widely used in Xhosa in its various lexical arguably, more original - functions.

In contrast to V-1 be in the full form, the element be grammaticalized as an invariant part of the contracted form has lost its independency. That is, the uninflected "bare" form be is not attested elsewhere in the language in any genuine verbal function, i.e. as a main, independent, lexical verb. The presence and use of the bare form be is restricted to the BE gram. 


\subsection{More cohesive properties of SVCs}

\subsubsection{Semantic cohesion - mono-eventhood}

The BE gram exhibits a high degree of semantic cohesion and complies with the mono-eventhood feature associated with the prototype of an SVC. That is, the construction - both in its full and contracted types - constitutes "one assertion" and communicates a single, unitary, and indivisible event. There is one semantic event expressed, not a complex of two consecutive or simultaneous events. Specifically, the BE gram communicates that something was occurring (past progressive sense - ndi-be ndi-dada 'I was swimming'), was in the state of occurring (past stative sense - ndi-be ndi-xakekeile 'I was busy'), had occurred (pluperfect sense - ndibe ndi-dad-ile 'I had swum'), or was going to occur / would be occurring (future-in-the-past or modal sense - ndi-be ndi-za kudada 'I was going to swim'). ${ }^{15}$

The mono-eventhood of the BE gram is corroborated by native speakers, who usually view the types of actions expressed by the BE gram as equivalent to simple verbal forms, and not as composed of two independent clauses denoting two separated events. Therefore, when asked to reformulate the $\mathrm{BE}$ gram by means of other expressions, the interviewed speakers regularly used TAM grams available in Xhosa rather than periphrastic expressions which could be interpreted in terms of bi-eventhood. For example, ndibe ndidlala was reformulated into the perfect / near past ndidlal-e/ile.

The mono-eventhood feature may be overtly demonstrated by the following behavior. Even in the full type, where verbal components are inflected independently, V-1 and V-2 cannot be accompanied by temporal or locative expressions that would locate them at different points in time or space. ${ }^{16}$ On the contrary, the event expressed by the BE gram is determined by identical temporal (6.a) and spatial (6.b) coordinants. As a result, any temporal or locative

15 The mono-eventhood of the BE gram in the future construction seems to be less unitary because future periphrases in Xhosa can sometimes be interpreted as venitive or allative. This, however, applies not to the BE gram per se (i.e. the slot ndibe ndiza / ben$d i z a$ ), but rather to the future-gram schema (ndiza $k u$-base). Nevertheless, in various instances, even this type of the BE gram expresses a single event, rather than a sequence or combination of two events.

16 This is possible in various multi-clausal constructions, e.g. in coordinated and subordinated clauses. 
operators (e.g. adjuncts such as adverbs or adverbial phrases, as well as adverbial clauses) obligatorily have their scope over the entire BE gram, not over one of its parts only. Accordingly, if a locative or temporal adjunct appears clause- or sentence-initially in the full BE gram (i.e. before V-1), it necessarily operates over V-2 as well - its scope cannot be restricted to V-1 (6.c). ${ }^{17}$

(6)
a. Ndi-b-e
ndi-dada
izolo
ngo 7 ngokuhlwa
I.SA-be-PERF
I.SA.SIT-swim
yesterday
at.7
at.15.evening
I was swimming yesterday at 7 in the evening
b. Ndi-b-e ndi-xakek-ile ekhaya I.SA-be-PERF I.SA.SIT-be.busy-PERF at.5.home I was busy at home
c. Nge-Cawa ba-b-e be-bukela umboniso-bha- $\begin{array}{lll} & \text { 2.SA-be-PERF 2.SA.SIT-watch } & \begin{array}{l}\text { nyabhanya } \\ \text { 3.show-flick- } \\ \text { ering }\end{array}\end{array}$

On Sunday, they were watching a movie (lit. a flickering show)

The scope of other types of adverbials - for instance, expressions of manner, means, and instrument - also extends over the entire BE gram, rather than over an individual component within it. This further demonstrates the mono-eventhood of the BE gram.
(7) Ndi-b-e
ndi-hamb-e
ngo-loliwe
I.SA-be-PERF
I.SA.SIT-go-PERF
by-1a.train
I had gone by train

As mentioned in Section 3.1.2, semantically, the event that is referred to by the BE gram always coincides with the lexical meaning of the verb that in

${ }^{17}$ It should be noted that expressions of time or place - or any other adjunct phrases - cannot intervene between $\mathrm{V}-1$ and $\mathrm{V}-2$.
(A) *USipho
u-b-e
izolo
e-dlala
1a.Sipho
1.SA-be-PERF yesterday
Intended meaning: Sipho was playing yesterday
1.SA.SIT-play 
the full type appears as V-2. That is, V-2 indicates the type of action, activity, situation, or condition that is expressed by the BE gram. In contrast, V-1 merely locates the event in the near past, thus contributing to the TAM of the BE gram. However, the form of V-2 also contributes to the overall TAM interpretation of the construction, as V-2 hosts markers of the (null) present, perfect / near past, or future (see Section 3.2.3). ${ }^{18}$

\subsubsection{Phonological cohesion - intonation}

In agreement with the SVC prototype, the BE gram exhibits a high degree of phonological cohesion. This observation applies not only to the synthetic, contracted form, but also to the analytical, full type.

To begin with, it should be noted that clauses built around the situative mood are often separated from the main or introductory clause (on which they syntactically and logically depend) by pause and contouring. In contrast, the phonological separation between V-1 and the situative form of V-2 found in the full type of the BE gram is significantly less evident. The full $\mathrm{BE}$ gram exhibits the intonation that is typical of a single mono-verbal clause rather than attesting to a prosodic pattern that is found in a sequence of clauses. Specifically, a fully audible pause - comparable to a break that separates coordinated or subordinated clauses - and contouring are not present between V-1 and V-2. Even more crucially, V-1 (i.e. the inflected form of the verb $b a$ 'be') does not exhibit the penultimate-vowel lengthening that typical appears at the end of a clause, an intonation group, or a (phonological) word (Jordan 1966: 15-16, Oosthuysen 2016: 4). Instead, it is pronounced short,

18 Given the value of the TAM categories exhibited on V-1 and V-2, it is possible to argue the following: $\mathrm{V}-1$ is responsible for the general time frame of the expression (i.e. near past), while V-2 indicates the ideas of simultaneity (expressed by the null-present form), anteriority or stativity (expressed by the perfect form), and prospectivity (expressed by the future form). Overall, the BE gram shows a certain affinity with asymmetrical SVCs where the invariant element tends to be grammaticalized into a TAM marker, while the variable component specifies the lexical type of the event. In the case of the BE gram, a part of the perfect form of $b a$-i.e. $b e$ - has been grammaticalized into the marker BE. However, as mentioned above, the TAM markers originally placed on V-2 are also necessary for the construction to be interpreted accurately in its three variants: progressive past, pluperfect / past stative, and future in the past (or conditional). 
and the lengthening usually appears on the vowel of the penultimate syllable of $\mathrm{V}-2 .{ }^{19}$

The phonological cohesion of the BE gram is even more evident in the contracted type. Here, the internal pause, the contouring, and the lengthening of the penultimate syllable of what originally was $\mathrm{V}-1$, are all - and by definition - impossible. Instead, the intonation is regularly mono-verbal, in harmony with other synthetic verbal forms in Xhosa. Therefore, in the modern Xhosa spelling, instances of this type of the BE gram are always written inseparably (Oosthuysen 2016: 238). ${ }^{20}$

\subsubsection{Morphosyntactic cohesion - shared TAM, shared polarity and shared arguments}

Both in its full and contracted form, the BE gram yields a single TAM interpretation, as it expresses a single event (see Section 3.2.1 above). I previously explained that the construction allows for the following readings: past progressive (ndibe ndidlala or bendidlala 'I was playing'), past stative (ndibe ndilambile / bendilambile 'I was hungry'), past perfect or pluperfect (ndibe ndidlalile / bendidlalile 'I had played') and future in the past or modality (ndibe ndiza/ya kudlala / bendiza/ya kudlala 'I was going to play / I would play').

Even though the BE gram expresses a single event bestowed with a unitary TAM value, the verbal components of the full type may be marked by different - sometimes semantically incompatible - TAM categories. This be-

19 It should be noted that from a typological perspective, not all subordinate clauses require pausal (comma) intonation. For instance, non-pausal (non-comma) intonation is typical of integrated clauses (Couper-Kuhlen 1996). This, however, is still compatible with the main point of the paper, since in the case of integrated clauses we are dealing with overt subordination, which does not qualify as an SVC (Aikhenvald 2006: 1). And as will be evident in section 3.2.4, the BE gram (even the full type) is not identical to prototypical subordination. It should also be observed that pause is not a compulsory feature of the phonological phrase boundary in Xhosa. Rather, the phonological phrase boundary is regularly indicated by the lengthening of the penultimate vowel and the tonal pattern, whereby the word-final high-tone is preserved (Jokweni 1995, Zerbian 2004: 72-74). However, as an optional device, the use of pause is grammatical in Xhosa and, in fact, often attested to (especially in left dislocation and certain types of clausecombining; cf. Zorbian 2004, Andrason \& Visser 2016), despite the fact that, in general, pause is not the typical marker of intonation breaks in Bantu (Downing \& Rialland 2017).

${ }^{20}$ However, in the mid $20^{\text {th }}$ century, the element be could still be written separately as illustrated by be ndidada 'I was swimming' (Jordan 1966: 181-184). 
havior contradicts the shared TAM principle postulated for the prototype of SVCs. To be exact, V-1 $b a$ is inflected in the perfect / near past of the indicative mood (8.a) or the relative mood (8.b). In contrast, V-2 is always inflected in the situative, exhibiting markers of the null present (8.c), the perfect / near past, and the future (8.b). ${ }^{21}$ Overall, there is no correlation between the TAM markers of V-1 with the TAM categories encoded on V-2.22

a. Ndi-b-e ndi-funda

I.SA-be-PERF I.SA-learn

I was studying

b. Umfundi o-b-e e-funda u-hamb-ile 1.student 1.SA.REL-be-PERF 1.SA.SIT-study 1.SA-go-PERF The student that was studying has left

c. Abafundi ba-b-e

be-ya ku-za 2.students 2.SA-be-PERF 2.SA.SIT-go INF-come The students were going to come

Since, in the contracted type of the BE gram, V-1 has been grammaticalized as a part of the TAM marking and the whole construction has become fused and synthetic, there is only one - albeit complex - TAM marker. Inversely, in the contracted form, there is only one genuine verb, the original $\mathrm{V}-2$, which is inflected in three possible TAM categories: past progressive (bendi-hamba 'I was walking'), past stative / past perfect (bendi-hamb-ile

${ }^{21}$ Infrequently, it may also be found in the subjunctive (Oosthuysen 2006).

${ }^{22}$ It should be noted that the components of the full type of the BE gram are limited to certain (even though relatively many) TAM categories. On the one hand, the verb $b a$ appears in the perfect / recent past, although, as already mentioned, there is an equivalent construction in which the verb $b a$ is inflected in the remote past tense. Very infrequently V-1 may be inflected in the present tense (Oosthuysen 2016: 246). On the other hand, V-2 obligatorily appears in the situative, specifically in its present, perfect and future variants. (This also applies to the other compound tense with the verb $b a$ in the remote past, the so-called A tense.) To conclude, even though the verbal components of the full types of the compound series of tenses can be inflected in various TAM categories, not all the TAM categories available in Xhosa can appear in these constructions. Such restrictions distance the BE gram (and similar grams) from the SVC prototype, which should tolerate all TAM categories (Aikhenvald 2006). 
'I had walked') and future-in-the-past (bendi-za/ya kuhamba 'I was going to walk'). Because the contracted type of the BE gram is mono-verbal, the 'shared-TAM' test cannot be applied.

As a holistic construction, the BE gram exhibits a unitary polarity interpretation. The event expressed by the gram was happening, had happened, was going to happen; or, on the contrary, it was not happening, did not happen, was not going to happen. In other words, the components of the BE gram cannot communicate negative and positive polarity, individually and separately, as is possible, for instance, in coordinated and subordinated constructions. This, however, does not imply that the polarity markers are correlated on $\mathrm{V}-1$ and $\mathrm{V}-2$ in the full type of the BE gram.

As is common in SVCs across languages, the negative marking is not shared by all the verbal components. Rather, the negation marker appears once and has the entire construction as its scope. Since, in the full type of the $\mathrm{BE}$ gram, the negative marker is hosted by $\mathrm{V}-2$, it exhibits the form typical of the situative mood. That is, the negator $n g a$ is prefixed to the base of V-2 that is additionally marked by the suffix $-i$ in the present and future (9.a), and the second $n g a$ in the perfect (9.b). The same markers operate in the contracted types, i.e. bendi-nga-dlal-i 'I wasn't playing' and bendi-nga-lamb-anga 'I wasn't hungry'.

(9) a. Ndi-b-e

ndi-nga-dlal-i

I.SA-be-PERF

I.SA.SIT-NEG.SIT-play-NEG

I was not playing

b. Ndi-b-e ndi-nga-lamb-anga

I.SA-be-PERF I.SA.SIT-NEG.SIT-be.hungry-NEG.PERF

I was not hungry

The BE gram complies with the shared-argument principle postulated for the SVC prototype. In the full type of the BE gram, there can only be one external, subject argument that operates over the entire construction, and thus over its two verbal components. This means that the subjects of V-1 and V-2 obligatorily coincide. The person or noun-class of the subject agreement pre- 
fixes of $\mathrm{V}-1$ and $\mathrm{V}-2$ is necessarily identical (10.a $)^{23}$ - each prefix referring to the same person, being, object, or idea (10.b). Inversely, the presence of distinct subject agreement markers on V-1 and V-2 - or two distinct subject referents - is disallowed (10.c). In the contracted type, there is usually only one subject agreement marker. Hence, the presence of two subjects separately is by definition impossible.
a. Ndi-b-e
ndi-gula
I.SA-be-PERF
I.SA.SIT-be.sick
I was sick

b. Ihashe

li-b-e li-balek-ile

5.horse 4.SA-be-PERF 5.SA.SIT-run-PERF

The horse had run (lit. The horse, it-was it-run)
c. *Ndi-b-e
si-lala
I.SA-be-PERF
we.SA-sleep

In the full type of the BE gram, the internal argument structure - in particular, the presence of primary or secondary objects - coincides with the valency pattern exhibited by $\mathrm{V}-2$. That is, if $\mathrm{V}-2$ is intransitive, the entire $\mathrm{BE}$ construction is intransitive (cf. ncokola 'chat' in 11.a); if V-2 is transitive the $\mathrm{BE}$ construction is transitive (cf. funda 'study something' in 11.b); lastly, if $\mathrm{V}-2$ is di-transitive, the same argument structure applies to the BE gram (cf. nika 'give something to someone' 11.c). Crucially, the two elements of the BE gram - viz. V-1 and V-2 - may never govern separate internal arguments, nor do they allow for duplicate roles.
a. Ba-b-e
be-ncokola
2.SA-be-PERF
2.SA.SIT-chat
They were chatting

${ }^{23}$ Of course, the two subject agreement markers may have different forms since the subject agreement marker of V-2 is typical of the situative, while that of V-1 is usually found in the indicative. Although the two sets of markers (i.e. the markers of the situative and those of the indicative) are usually identical, they differ for a few noun classes. 

b. Ndi-b-e
ndi-funda
isiXhosa
I.SA-be-PERF I.SA.SIT-study
7.Xhosa.language
I was studying the Xhosa language
c. Umama u-b-e e-nik-e inkwenkwe imali
1a.mother 1.SA-
1.SA.SIT-be-PERF 9.boy
9.money -be-PERF

The mother had given the boy money

In the contracted type, the argument structure of the BE gram - both in respect to internal and external arguments - is projected by the valency pattern of the main verb, the original V-2.

In Xhosa, verbs may also exhibit object agreement markers. In transitive and di-transitive constructions found in the full form, the object agreement markers are hosted by $\mathrm{V}-2$, which as explained determines the valency patters of the BE gram (12.a). In the contracted form, object agreement appears immediately before the base of the main verb.
a. Ndi-b-e
ndi-m-bon-ile
I.SA-be-PERF
I.SA.SIT-1.OA-see-PERF
I had seen him
b. Be-ndi-m-bon-ile
BE-I.SA-1.OA-see-PERF
I had seen him

\subsubsection{Mono-predicativity and mono-clausality}

The issue of the mono-predicativity and mono-clausality of the BE gram is a complex matter. The two types of the $\mathrm{BE}$ gram respond differently to that criterion - each type eluding a classification into neat, binary terms of either-or.

The full type of the BE gram seems not to comply with the mono-predicativity and mono-clausality features. Both features disallow one of the components of an SVC to be syntactically dependent on the other, for instance by being marked by dependency morphemes, typical of subordinate/dependent 
clauses (Aikhenvald 2006: 6, Dixon 2006, Bisang 2009: 796). In the case of the full type of the BE gram, at least formally, the construction contains two predicative and even clausal slots of which one (viz. V-2) exhibits overt markers of syntactic dependency appearing in the situative.
Umfundi
u-b-e
e-sebenza
1.student
1.SA-be-PERF
1.SA.SIT-work
The student was working (lit. he-working)

The situative mood is a dependent construction in Xhosa that complements other parts of the sentence (Jordan 1966: 82, Du Plessis 1978). Functionally, the situative approximates participles and gerunds of Indo-European languages, although it exhibits subject agreement inflectional prefixes, thus constituting a finite category in Xhosa. It is often introduced by or subordinated to another predicate. The subjects of the situative and that introductory predicate may coincide (14.a) or they may be distinct (14.b). The subject of the situative may also coincide with internal arguments (e.g. primary or secondary objects) or adjuncts of the introductory - superordinate - verb (14.c). ${ }^{24} \mathrm{In}$ a structural representation, a sentence containing a situative verb is analyzed as composed of (at least) two clauses: the main clause and the dependent clause with the situative verb (Du Plessis 1978: 136-137). This also implies a two-predicate structure (ibid.).
a. Ba-ncokola be-sebenza
2.SA-chat
2.SA.SIT-work
They are chatting (while) working
b. USipho
u-ya-sebenza
e-dlala
uLandile
1a.Sipho
1.SA-PRES-work
1.SA.SIT-play
1aLandile
Sipho works while Landile is playing

24 Apart from its dependent usage described above, the situative appears after certain conjunctions (e.g. $x a$ 'when'), the interrogative particle kutheni 'why?', and auxiliary verbs such as soloko '(do) often' sele '(do) already'. Such uses derive from the dependent nature of the situative. For instance, the use with $x a$ 'when' is a more grammaticalized stage of the dependent expression in which the element $x a$ was used as a noun 'time', i.e. 'time [at which]'. 


\section{c. Ndi-bon-e abantwana be-dlala I.SA-see-PERF 2.children 2.SA.SIT-play I saw the children play(ing) / (while) they were playing}

Although V-2 exhibits the marker of the situative in the full type of the BE gram and, at least formally, functions as a dependent clause subordinated to the main clause and V-1, the degree of bi-clausality seems to be lower than in the other uses of the situative described in the previous paragraph. Sentences in examples (14.a-c) are, without doubt, composed of two clauses. The clause containing the verb in the situative is formally and logically subordinated to the main clause. In contrast, in the full type of the BE gram, even though $\mathrm{V}-2$ is formally marked for syntactic dependency (i.e. V-2 exhibits a situative form), it is not logically dependent on V-1. This stems from the mono-eventhood of the entire construction and its interpretation as a single event, not a combination of two events (see Section 3.2.1). Contrary to canonical situative constructions, the BE gram expresses one action or activity; the "main" verb (V-1) and the "dependent" verb (V-2) cannot be accompanied by distinct temporal and locative expressions; their subjects must coincide; the chain of the two verbs usually cannot be interrupted; and the bi-clausal intonation is absent (see Section 3.2.1, 3.2.2, and 3.2.3).

Furthermore, in contrast to exemplary bi-clausal structures, V-1 and V-2 of the full type of the BE gram cannot usually be separated by the nominal subject. Although there are sporadic instances where the subject does appear between $\mathrm{V}-1$ and $\mathrm{V}-2$, by far the most natural and the most common word order is: [subject $+[\mathrm{V}-1+\mathrm{V}-2]]$ or $[[\mathrm{V}-1+\mathrm{V}-2]+$ subject]. Accordingly, as the nominal subject (expressed by a noun or an absolute pronoun) operates over the entire predicate, appearing either before or after it, the two verbs behave as a single clause or a single predicative slot in a clause..$^{25}$

In the contracted type of the BE gram, syntactic dependency is even less evident than it was the case of the full type. In fact, the contracted forms may be analyzed as exhibiting a mono-clausal and a mono-predicative structure.

25 The bi-clausality of SVCs may also be evident through coordination, consecutivization, and the use of complement clauses. However, these devices are not utilized by the $\mathrm{BE}$ gram. That is, the full form of the BE gram is distinct from coordinated and consecutive structures in Xhosa, which are introduced by the subjunctive and the consecutive, as well as by clauses introduced by kwaye, yaye and similar particles. 
Certainly the "frozen" remnants of the situative morphology persist as monosyllabic verbs and verbs that begin with a vowel still exhibit the morpheme $s(i)$ - a typical sign of the situative. However, given that V-1 has lost its verbal status and has been grammaticalized into an invariant part of the TAM marker, it no longer constitutes an independent predicate that would govern its own clause. There is only one predicate in the construction - i.e. the original V-2, itself reanalyzed as the main verb. Only one clause can be built around that verb.

\section{Discussion}

The evidence demonstrates that neither the full type nor the contracted type of the BE gram complies in all aspects with the SVC prototype. Even though the two types fulfill many features characterizing SVCs across languages, both violate a few fundamental criteria.

The full type of the BE gram behaves as an SVC in most aspects. It complies with the bi-verbiness and independency features, which are responsible for the less cohesive facet of SVCs crosslinguistically. It also fulfills various semantic, phonological, and morpho-syntactic criteria that ensure the cohesive nature of SVCs. The full type of the BE gram constitutes "one assertion", expressing a single event rather than a sequence of separate events. It exhibits cohesive intonation typical of mono-verbal clauses. It conveys a single polarity and TAM value, being also characterized by a unitary argument structure. Specifically, even though negation is only marked on V-2, it operates over the entire construction such that an independent choice or contrast in polarity is not possible. The components of the full type of the BE gram do not project duplicate roles nor do they govern separate arguments. The subject argument belongs to the entire construction, being invariably shared by V-1 and V-2. Similarly, even though the internal arguments draw on the valency pattern of $\mathrm{V}-2$, any object of the BE gram is the property of the entire construction. However, contrary to the prototype of an SVC, the TAM marking of V-1 and V-2 is not correlated as the two verbs may be inflected in different, even, in principle, incompatible TAM categories. Likewise, the full type of the BE gram generally fails to comply with the mono-predicativity and mono-clausality properties associated with the prototype of an SVC. Formally, it constitutes a type of a bi-clausal (and hence bi-predicative) structure. In this structure, V-2 is marked for syntactic dependency with regard to V-1, 
appearing in the situative. However, even though formal dependency is unmistakable, logical dependency can be questioned. Overall, the bi-clausality of the full type of the BE gram is less evident than the bi-clausality exhibited in similar sequences that are composed of a main clause and a subordinate clause containing a verb in the situative. This lesser extent of dependency stems from the mono-eventhood of the BE gram and its profound semantic, phonological, and morpho-syntactic cohesion, absent in the clearly bi-clausal (situative) sequences.

The contracted type of the BE gram also complies with certain traits postulated for the SVC prototype. Specifically, all the features responsible for the cohesive facet of an SVC are met: mono-eventhood, mono-verbal phonology, single TAM interpretation, unitary polarity value, and shared argument structure. The contracted type of the BE gram is also mono-predicative and mono-clausal. There is in fact only one verb (predicate) in the construction - V-1 (be) having been reanalyzed as an invariant part of the complex inflectional marker. As a result, the bi-verbiness condition is violated - the construction is a fused synthetic gram in which only one verb is inflected. Moreover, the element be has lost its independency. Its "bare" form (i.e. be) is not attested as a full verbal form elsewhere in the language, but is restricted to the BE gram.

The above results indicate a qualitative difference in the non-compliance of the two types of the BE gram with the SVC prototype. The full type is excessively "disjunctive" or, inversely, insufficiently cohesive. At least in some aspects, it is bi-clausal and bi-predicative, violating the principles of monoclausality and mono-predicativity. In contrast, the contracted type is excessively cohesive or insufficiently "disjunctive". It is mono-verbal, failing to comply with the criterion of bi-verbiness.

All of this allows me to now answer the question posed at the beginning of the research: is the BE gram an SVC? The study demonstrates that the $\mathrm{BE}$ gram does not constitute a canonical instantiation of an SVC. Given the above, a new problem emerges. If the BE gram is not a canonical SVC, what is the extent with which it differs from the SVC prototype? Is it (slightly) less canonical, non-canonical, or located outside the SVC category?

If one adopts an essentialist position, focusing on the critical or fundamental features of SVCs such as the simultaneous presence of mono-predicativity/clausality and bi-verbiness, the BE gram would be categorized as external to the SVC category. On the one hand, the absence of clear mono-clausality 
and mono-predicativity would exclude the full type of the BE gram from the realm of SVCs. On the other hand, the lack of the bi-verbiness would make it impossible to classify the contracted BE gram as an SVC.

Given the prototype-driven, fuzzy, and dynamic nature of real-world categories, the essentialist position seems excessively artificial and the classification of the BE gram as extra-categorial too simplistic. In my view, at least the full type of the BE gram may be analzyed as relatively proximate to the SVC prototype, constituting its slightly less canonical instantiation. I will explain this in the remaining part of the paper.

As has been explained in Section 2, a number of SVCs attested across languages may derive from coordinated or subordinated structures by gradually increasing their cohesion. Coordinated structures - i.e. clauses connected through a conjunctive coordinator - constitute a particularly productive source of SVCs. Given this origin, some SVCs may exhibit a morpho-phonemic structural element that is a remnant of the original conjunctive coordinator (see, for instance, the so-called linker in various pseudo-coordinated constructions). This element, however, is not a genuine conjunctive coordinator any more. Rather, by losing its typical semantic, phonological and syntactic properties, it constitutes an "atavistic" relic - an empty marker, merely attesting to the diachronic origin of the construction (Andrason forthcoming). Overall, such constructions still belong to the SVC category (cf. Aikhenvald 2006, 2011). If they comply with the remaining features, their divergence from the prototype is in fact minimal.

The gradient-dynamic nature of the SVC category and the understanding of constructions exhibiting remnants of overt coordination as less prototypical SVC instantiations implies the following: more cohesive successors of other types of bi-clausal and bi-predicative structures should belong to the SVC category as well. Such other types include constructions built around syntactic dependency (see Aikhenvald 2011). In agreement with the progress experienced by coordination-sourced SVCs, as the construction increases its phonological, semantic, and morpho-syntactic cohesion, the presence of what originally was a dependency marker may not be a true sign of dependency but rather an "atavistic" relic of the construction's diachronic past. If the gram exhibits the other typical features of the SVC prototype, it would constitute a marginally less canonical instantiation of the SVC category. 
Transposing this theoretical argument to the topic of my study, viz. the BE gram, the following can be proposed: in the full type, the dependent (situative) marking of V-2 may be interpreted as an atavistic feature - a remnant comparable to empty coordination markers found in some SVCs. Although formally the full type of the BE gram exhibits a bi-clausal structure (which attests to its diachronic source), this dependency would not be genuine. As explained, the full type of the BE gram differs in many aspects from exemplary bi-clausal structures built around syntactic dependency (e.g. mono-eventhood, argument sharing, temporal and spatial identity, mono-clausal phonology, and the position of the subject). As a result, this type of the BE gram can be understood as a marginally less canonical SVC.

The distance from the prototype may even be lesser for a certain subgroup of the full BE grams. For various noun classes and persons (in fact, for the majority of them), the markers of the situative and indicative are indistinguishable. Moreover, for all consonant verbs and verbs exhibiting more than one syllable (which comprises the large majority of verbs in Xhosa), the situative marker $s(i)$ is absent. In all such cases where the inflectional patterns of the indicative and the situative coincide, even the overt, formal dependency of $\mathrm{V}-2$ is (virtually) absent. Forms such as ndi-be ndi-hamba 'I was walking' or li-be li-dada 'it [e.g. idada 'a duck'] was swimming') do not differ from a sequence of two indicative verbs that do not exhibit any overt trace of dependency, coordination, or consecutivization. ${ }^{26}$ In that manner, these structures would act as prototypical SVC schemas. The prevalence of such joint indicative-situative patterns in the Xhosa language, in general, and in the full BE forms, specifically, may have important bearings on the (perception of the) dependency status of cases where V-2 is formally marked. The dependency of such examples - only seen formally and already undermined logically - may further be weakened by analogy to the dominant pattern in which the formal dependency marking is "invisible". ${ }^{27}$

${ }^{26}$ In some instances, however, the difference may involve tone. As the tonal pattern found in the situative may differ from the tonal pattern of the indicative (Oosthuysen 2016:208), the form of V-2 of the BE gram would be (marginally) different from its indicative counterpart.

27 It should be noted that the resulting structure (indicative V-1 + indicative V-2) is one of the ways in which verbal clauses can be conjoined in Xhosa - an asyndetic coordinative pattern, e.g. ziyatheza ziyabasa 'they make fire [and] cook' (Du Plessis \& Viss- 
As a result, from a dynamic and fuzzy perspective, the full type of the BE gram could be analyzed as a nearly canonical representative of the SVC category. That is, at least for the full type of the BE gram (and especially for its variants in which V-2 is indistinguishable from the indicative), the SVC-hood of the BE gram could be successfully argued. Its presence in Heine's and Aikhenvald's typological studies would, therefore, be fully justified.

As far as the contracted type of the BE gram is concerned, this variant could be viewed as a considerably non-prototypical instantiation of the SVC category, rather than an entirely extra-categorial phenomenon. Certainly, the highly cohesive profile exhibited by this construction separates it from the SVC prototype quite effectively, probably locating it in the (extreme) periphery of the SVC category. However, this separation may not be complete(d) as remnants of the bi-verbal structure may still be observed in the weak classes. In such cases, the verb be may be analyzed as inflected (or, at least, accompanied by what originally was its subject agreement marker), allowing for a biverbal interpretation. As a result, V-1 could be used on its own and the independency criterion would be (at least theoretically) met.

\section{Conclusion}

The present paper demonstrated that the categorial status of the BE gram is a complex matter that cannot be accurately addressed within a neat, essentialist, binary, and static paradigm. The more precise and meaningful manner of dealing with the BE gram - and SVCs in general - is to approach it from a prototype-driven, radial-network, dynamic perspective. From that perspective, the full type of the BE gram can be viewed as a less canonical member of the SVC category, while the contracted type constitutes its highly non-canonical instantiation. The categorial difference between the two types stems from their dissimilar advancement on the grammaticalization path leading from less cohesive to more cohesive schemas. This understanding of the BE

er 1993: 75). More often, however, especially if the nuance of sequentiality is to be conveyed, Xhosa uses the subjunctive mood or the consecutive mood depending on whether the reference time-frame is present-future or past, respectively (cf. ndivuke...ndanxiba 'I woke up [and then] I dressed up'; Du Plessis \& Visser 1992, 1993). Clauses can also be linked in a syndetic manner through coordinators such as $k w a-$ and $k w a y e$ (Du Plessis \& Visser 1993). 
gram, in turn, corroborates the view that, apart from coordination, the category of SVCs may crosslinguistically have dependent clauses (including subordination) as its diachronic input (Aikhenvald 2011).

\section{Abbreviations}

ADJ - adjective concord; ASSIM - assimilated / assimilation; BF - buffer; INF infinitive; LOC - locative; NEG - negation / negator; OA - object agreement; PERF - perfect / near past; PRES - present; R - root/stem/base; SA - subject agreement; SIT - situative; SVC - serial verb construction; TAM - tense, aspect, mood; 1-15 - noun classes.

\section{References}

Aikhenvald A., 2006, Serial verb constructions in typological perspective, In: A. Aikhenvald A., Dixon R. M. W. (eds.), Serial Verb Constructions: A Crosslinguistic Typology, Oxford: Oxford University Press, p. 1-68.

Aikhenvald A., 2011, Multi-verb Constructions: Setting the Scene, In: A. AikHenvald, P. Muisken (eds.), Multi-verb Constructions: A View from the Americas, Leiden: Brill, p. 1-26.

Aikhenvald A., Dixon R. M. W. (eds.), 2006, Serial Verb Constructions: A Crosslinguistic Typology, Oxford: Oxford University Press.

Andrason A., 2016a, A Complex System of Complex Predicates: Tense, Taxis, Aspect and Mood in Basse Mandinka from a Grammaticalization and Cognitive Perspective, PhD dissertation, Stellenbosch: Stellenbosch University.

ANDRAson A., 2016b, From vectors to waves and streams: An alternative approach to semantic maps. Stellenbosch Papers in Linguistics 45, p. 1-29.

ANDRASON A., 2018a, From coordination to verbal serialization - The PÓJŚĆ (serial verb) construction in Polish, Research in Language 16(1), p. 19-46.

ANDRASON A., 2018b, A pseudo-consecutive non-canonical serial verb construction in isiXhosa. Stellenbosch Papers in Linguistics Plus 55, p. 1-6.

Andrason A.,Visser M. W., 2016, The mosaic evolution of Left Dislocation in Xhosa. Stellenbosch Papers in Linguistics 50, p. 139-158.

Bastin Y., Coupez A.,Mann M., 1999, Continuity and Divergence in the Bantu Languages, Tervuren: Musée Royale du Afrique Centrale.

BISANG W., 2009, Serial verb constructions, Language and Linguistics Compass 3(3), p. $792-814$. 
Bryant A., 2007, Xhosa for Second-Language Learners, South Africa: Alexandra Bryant Publisher.

Couper-Kuhlen E., 1996, Intonation and clause combining in discourse, Pragmatics 6(3), p. 389-426.

Croft W., 2003, Typology and Universals, Cambridge: Cambridge University Press.

Dixon R. M. W., 2006, Serial verb constructions: Conspectus and coda, In: A. AIkhenvald, R. M. W. Dixon (eds.), Serial Verb Constructions: A Cross-linguistic Typology, Oxford: Oxford University Press, p. 338-350.

Doke C. M., 1981, Textbook of Zulu Grammar, Cape Town: Longman Southern Africa.

Downing L. J. \& A. Rialland (eds.), 2017, Intonation in African Tone Languages, Berlin: De Gruyter Mouton.

Du Plessis J. A., 1978, IsiXhosa 4, Goodwood: Oudiovista.

Du Plessis J. A., Malinga R., 1978, IsiXhosa 3, Goodwood: Oudiovista.

Du Plessis J. A., Visser M., 1992, Xhosa Syntax, Pretoria: Via Afrika.

Du Plessis J. A., Visser M., 1993, Co-ordination and the subjunctive in Xhosa, South African Journal of African Languages 13, p. 74-81.

Gowlet D., 2003, The S-Group, In: D. Nurse, G. Philipson (eds.), The Bantu languages, London: Routledge, p. 609-638.

Groenewald H. C., 2014, A re-evaluation of tenses in isiZulu, Literator 35(1). Art. 1062, p. 1-8. http://dx.doi.org/10.4102/lit.v35i1.1062

Guthrie M., 1970, Comparative Bantu: An Introduction to the Comparative Linguistics and Prehistory of the Bantu Languages. Vols. 1-4, Farnborough: Gregg Press.

Hall L., 2005, The BE Relative Tenses of Zulu, MA dissertation, Pretoria: University of Pretoria.

Haspelmath M., 2003, The geometry of grammatical meaning semantic maps and cross-linguistic comparison, In: M. Tomasello (ed.), The New Psychology of Language, Mahwah: Lawrence Erlbaum Associates, p. 211-242.

Haspelmath M., 2016, The serial verb construction: Comparative concept and crosslinguistic generalizations, Language and Linguistics 17(3), p. 291-319.

Heine B., 1993, Auxiliaries: Cognitive Forces and Grammaticalisation, New York: Oxford University Press.

JANDA L., 2015, Cognitive linguistics in the Year 2015, Cognitive Semantics 1, p. 131-154 .

Jokweni M. W., 1995, Aspects of Isixhosa Phrasal Phonology, PhD dissertation, Champaign: University of Illinois.

Jordan A. C., 1966, A Practical Course in Xhosa, Johannesburg: Longmans.

Louw J. A., Jubase J. B., 1963, Handboek van Xhosa, Johannesburg: Bonapers Beperk. 
McLaren J., Wlesh G. H., 1955, A Xhosa Grammar, Cape Town: Longmans, Green Co.

NArrog H., VAN der Auwera J., 2011, Grammaticalization and semantic maps, In: H. Narrog H., Heine B. (eds.), The Oxford Handbook of Grammaticalization, Oxford: Oxford University Press, p. 318-327.

Nurse D., 2008, Tense and Aspect in Bantu, Oxford: Oxford University Press.

Oosthuysen J. C., 2016, The Grammar of isiXhosa, Stellenbosch: Sun Media.

Pelling J., P. Pelling, 1974, Lessons in Ndebele, Salisbury: Longman Rhodesia.

Posthumus L. C., 1982, A review of the so-called -be/-ba past tenses of Zulu, South African Journal for African Languages 2(2), p. 94-108.

Posthumus L. C., 1983, Werkwoordkategorië in Zulu, Unpublished manuscript, Bloemfontein: Universiteit van die Oranje Vrystaat.

Posthumus L. C., 1990, Time reference in Zulu, South African Journal for African Languages 10(1), p. 22-28.

Posthumus L. C., 2006, The spectrum of the -be relative tenses of Zulu, South African Association for Language Teaching 40(1), p. 100-116.

Posthumus L. C., 2008, Naming the so-called continuous past tenses of the southeastern Bantu languages with particular reference to Zulu, South African Journal of African Languages 28(1), p. 69-79.

Poulos G., Msimang C. T., 1998, A Linguistic Analysis of Zulu, Cape Town: Via Afrika.

Riordan J., Mathiso M., Davey A. S., 1969, Lumko Xhosa Self-Instruction Course, Grahamstown: Institute of Social and Economic Research, Rhodes University.

Taaljard P. C., Bosch S. E., 1988, Handbook of isiZulu, Pretoria: J. L. van Schaik.

Taaljard P. C., Khumalo J. N., Bosch S. E., 1991, Handbook of siSwati, Pretoria: J. L. van Schaik.

TAYlor J. R., 2003, Linguistic Categorization, Oxford: Oxford University Press.

Tshabe S. L. (ed.), 2006, The Greater Dictionary of isiXhosa. Vol 1, Fort Hare: University of Fort Hare.

VAN Eeden B. I. C., 1956, Zoeloe-grammatika, Stellenbosch: Die Universiteitsuitgewers en Boekhandelaars Beperk.

Visser M. W., 2005, Xhosa, In: K. Brown (ed.), Encyclopedia of Language and Linguistics, Oxford: Elsevier, p. 705-716.

Visser M. W., 2015, Xhosa 2014, 244. Syntax, Stellenbosch: University of Stellenbosch.

Zerbian S., 2004, Phonological phrasing in Xhosa. ZAS Papers in Linguistics 37, p. 71-99.

Ziervogel D., 1959, A Grammar of Northern Transvaal Ndebele, Pretoria: Van Schaik. 


\section{Czas złożony z formą BE w języku Xhosa (Nguni, Bantu) jako szeregowa konstrukcja czasownikowa \\ (streszczenie)}

W artykule przedstawiono kognitywną analizę statusu taksonomicznego konstrukcji BE w języku Xhosa (Nguni, Bantu) w ramach typologicznej teorii czasowników szeregowych (serial verb construction). Porównanie omawianej konstrukcji z prototypem czasowników szeregowych dowodzi, iż podtyp "pełny" konstrukcji $\mathrm{BE}$ jest kanonicznym reprezentantem kategorii czasowników szeregowych, podczas gdy podtyp "skrócony" jest reprezentantem niekanonicznym. Różnica taksonomiczna między dwoma podtypami wynika z niejednolitego postępu w gramatykalizacji wiodącej od konstrukcji niespójnych do konstrukcji spójnych. Artykuł ukazuje, iż obok współrzędnych, konstrukcje podrzędne i zależne mogą stanowić źródło diachroniczne kategorii czasowników szeregowych. 
